Cite this article as: BMJ, doi:10.1136/bmj.39022.436389.BE (published 15 May 2007)

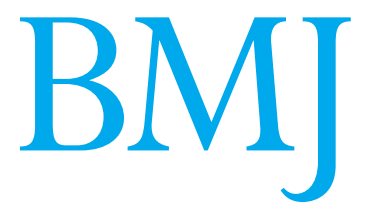

RESEARCH

\title{
Side effects of phenobarbital and carbamazepine in childhood epilepsy: randomised controlled trial
}

\author{
Selina H Banu, clinical neurophysiologist and paediatric neurologist, ${ }^{1}$ Moshrat Jahan, primary care physician \\ trained in childhood epilepsy, ${ }^{,}$Umme Kulsum Koli, child psychologist, "Saadia Ferdousi, child psychologist, \\ Naila Z Khan, professor of child development and neurology, ${ }^{1}$ Brian Neville, Prince of Wales's professor of \\ childhood epilepsy²
}

$\overline{{ }^{1} \text { Child Development and Neurology }}$ Unit, Dhaka Shishu (Children's)

Hospital, Bangladesh Institute of

Child Health, Sher-e-Bangla Nagar,

Dhaka 1207, Bangladesh

${ }^{2}$ Neurosciences Unit, UCL,

Institute of Child Health, Wolfson Centre, London WC1N 2AP

Correspondence to: $B$ Neville bneville@ncype.org.uk

doi: 10.1136/bmj.39022.436389.BE

This is version 2. Several errors came to light after online publication, which have now been corrected. The definitions of epilepsy have been clarified in the methods section and table 1. Details of timing of seizures in follow-up has been clarified in table 2 . In the figures the number of children who continued to take phenobarbital has been corrected to 40 (from 42). The penultimate paragraph of the results section has been changed extensively to further clarify results.

\section{ABSTRACT}

Objective To compare the behavioural side effects associated with two commonly used antiepilepsy drugsphenobarbital and carbamazepine-in children in Bangladesh.

Design Prospective randomised controlled single centre trial.

Setting Specialist children's hospital in Dhaka,

Bangladesh.

Participants 108 children aged 2-15 with generalised tonic-clonic $(n=51)$ or partial and secondary generalised seizures $(n=57)$.

Main outcome measures Seizure control and behavioural side effects.

Results 91 children were followed up for 12 months. Six required a change of antiepilepsy drug. Side effects were compared in 85 children. In the last quarter of the 12 month follow-up, 71 children were seizure free after one year's treatment. Thirty two in the phenobarbital group and 39 in the carbamazepine group had no seizures for 74 and 102 days after randomisation, respectively. Ten children had increased behavioural problems, which were unacceptable in four (one in the phenobarbital group and three in the carbamazepine group). Independent $t$ tests, however, showed no difference between the two trial drugs.

Conclusion There was no excess in behavioural side effects with phenobarbital in children with epilepsy in a country with limited resources.

Trial registration NCT00381537.

\section{INTRODUCTION}

Epilepsy is the most common neurological disorder in children; $80 \%$ of affected children live in countries with limited resources where $90 \%$ of epilepsy is not consistently treated. ${ }^{1}$ For a sustainable treatment programme antiepilepsy drugs must be affordable, available, and effective and have minimal side effects.

The World Health Organization recommends phenobarbital as the first choice of drug for most seizures and epilepsies in developing countries mainly because of cost, but carbamazepine is also recommended for all but typical absences ${ }^{23}$ and is used in Bangladesh. ${ }^{4}$ Several studies have shown that 30-50\% of children treated with phenobarbital experience behavioural side effects, ${ }^{5-8}$ and one study showed a persistent reduction in IQ. ${ }^{9}$ Others have found no such effect. ${ }^{10-12}$ There is a need for robust evidence about the use of phenobarbital, ${ }^{13}{ }^{14}$ particularly in areas with limited resources.

We compared the behavioural side effects of phenobarbital and carbamazepine in a Bangladesh clinic.

\section{METHODS}

We carried out a double blind randomised controlled trial from the multidisciplinary child development centre at a children's hospital. ${ }^{4}$ Children were recruited by clinical referral from April to October 2001 and followed up for 12 months.

From previous studies we hypothesised a $25 \%$ excess of behavioural side effects with phenobarbital compared with carbamazepine. With a predicted rate of side effects of $15 \%$ in carbamazepine and a $25 \%$ difference between the two groups, for $80 \%$ power at $5 \%$ significance (two tailed) we calculated that we would need 46 children in each group. ${ }^{15}$ Allowing for a $20 \%$ drop out rate, we planned to enrol 54 children into each group.

Children were aged 2-15 years with "active epilepsy" defined as two or more generalised tonic-clonic, partial or secondary generalised seizures during the previous year. Exclusions were absence, myoclonic or severe malignant epilepsy, major motor and cognitive impairments, or current treatment with antiepilepsy drugs. We included children with minor non-epilepsy impairments who were able to carry out age appropriate, independent daily living activities.

All parents gave written informed consent. We obtained a history of seizures, associated neurodevelopmental problems, pregnancy and birth related problems, early development, immunisation, and family and socioeconomic information from patients, parents, and family members. All children underwent electroencephalography; other investigations were performed as clinically indicated. We used a standard classification of seizures, epilepsies, and epilepsy syndromes, ${ }^{1617}$ modified for limited investigations ${ }^{4}$ 


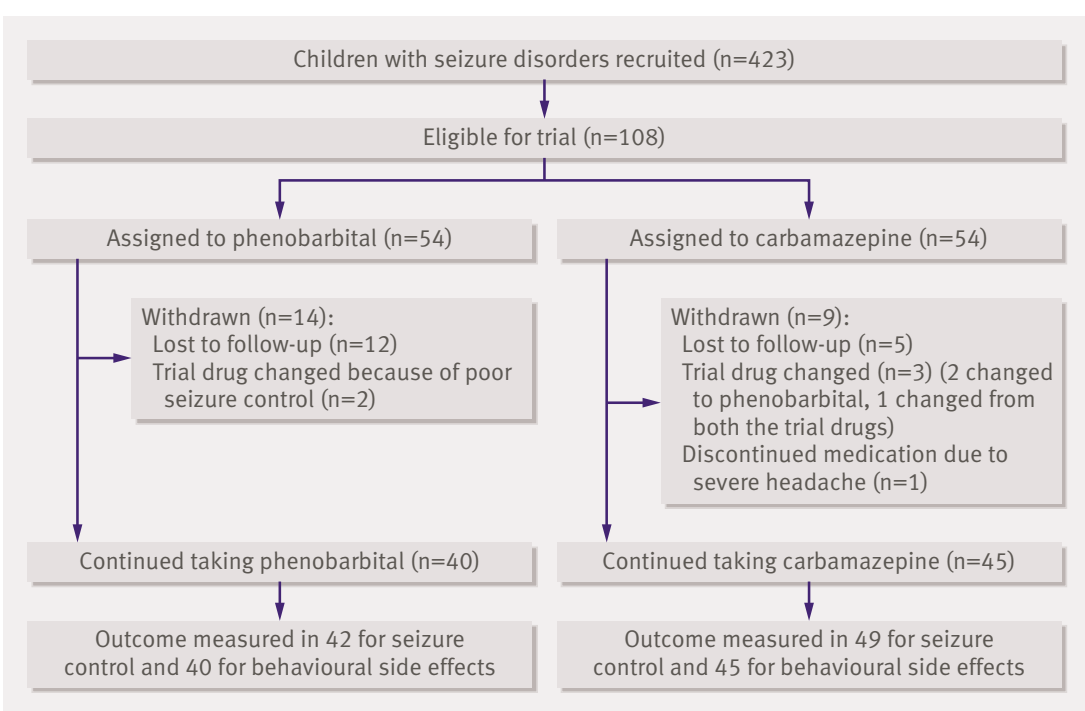

Flow of children through the trial behaviour as acceptable or unacceptable on the basis of parental concern.

On entry, participants were randomly assigned to treatment with phenobarbital or carbamazepine. One researcher $(\mathrm{SHB})$ prepared 108 envelopes containing a paper designating drug A or B. These were sealed, shuffled, and kept securely. An independent assistant selected an envelope after a telephone request from the treating physician. For practical and ethical reasons the treating physician was aware of the allocation but the psychologist, therapist, and researcher were blind. The researcher was unblinded at data analysis.

We reviewed patients at two weeks, one month, three months, and six months interval after randomisation, depending on therapeutic response and travel. Compliance was measured by verbal reply, counting tablets, and blood concentrations of antiepilepsy drugs in samples taken on a single occasion without notice.

Phenobarbital and carbamazepine (immediate release) were available as strips of $30 \mathrm{mg}$ and

by using the two categories of syndrome: symptomatic including cryptogenic and without other impairments.

Children underwent an initial general and central nervous system examination and multidisciplinary assessment of functional neurodevelopment. ${ }^{18}$ Psychological assessments used were the Bayley scale of infant development (BSID) for those aged 2-3 years, ${ }^{19}$ the independent behaviour assessment scale (IBAS) for those aged 3-6 years, ${ }^{20}$ and Wechsler intelligence scales for children-revised (WISC-R) for those aged $\geq 16$ year. 2122 Cognitive level was designated "normal" or "impaired," with a cut-off IQ of 70.

We assessed behaviour using age appropriate behavioural screening questionnaires, which we and others have used in similar settings. ${ }^{2123}$ We used the Bayley scale ${ }^{18}$ for those aged $\leq 2$ years and the Richman behavioural assessment questionnaire for those aged 2 years 1 month to 3 years 11 months. ${ }^{24}$ Many similar studies have used Conners' rating scale-revised for children aged $5-15 .{ }^{25}$ We reassessed behaviour after 12 months of treatment or at drug withdrawal using the same assessment scale.

The Conners' short questionnaire for parents (CPRS-R:S) was translated from English into Bangla, revised after feedback about common use, and tested for reliability and concurrent validity measure.

We examined test and re-test reliability on 20 children at an interval of two weeks for each index and found no significant difference, which suggests that parental responses were reliable and stable. ${ }^{26}$ The concurrent validity test with a standard Rutter test $^{2728}$ showed a good correlation ( 0.74 with two tailed significance at $\mathrm{P}<0.01$ ).

We categorised behavioural state as "no change," "improved," or "deteriorated" compared with entry condition on the basis of behavioural assessment questionnaires and subcategorised deteriorated
Table 1 |Characteristics of children with epilepsy and their families according to allocation to antiepilepsy drug (54 children in each group): baseline data. Figures are numbers of children unless stated otherwise

\begin{tabular}{lccc} 
Family type: & Phenobarbital & Carbamazepine & Total \\
\hline Nuclear* $^{*}$ & 33 & 35 & 68 \\
\hline Joint† & 21 & 19 & 40 \\
\hline Residence: & & & \\
\hline Rural & 35 & 32 & 67 \\
\hline Urban & 19 & 22 & 41
\end{tabular}

Socioeconomic status by monthly income:

\begin{tabular}{lccc}
\hline Poor & 20 & 33 & 53 \\
\hline Middle income & 32 & 13 & 45 \\
\hline Higher income & 2 & 8 & 10 \\
\hline $\begin{array}{l}\text { Maternal literacy: } \\
\text { None }\end{array}$ & 25 & 19 & 44 \\
\hline Primary & 16 & 16 & 32 \\
\hline $\begin{array}{l}\text { Secondary } \\
\text { school }\end{array}$ & 7 & 9 & 16 \\
$\begin{array}{l}\text { Higher secondary } \\
\text { school }\end{array}$ & 2 & 3 & 5 \\
\hline Further education & 4 & 7 & 11 \\
\hline $\begin{array}{l}\text { Sex: } \\
\text { Male }\end{array}$ & 37 & 24 & 61 \\
\hline Female & 17 & 30 & 47 \\
\hline
\end{tabular}

Age at onset (years):

\begin{tabular}{lccc}
\hline$\leq 1$ & 13 & 8 & 21 \\
\hline$>1$ & 41 & 46 & 87 \\
\hline Median (IQR) (years) & $2.4(1.2-5.3)$ & $3(1.6-6.3)$ & $3(1.6-6)$
\end{tabular}

Age at presentation (years):

\begin{tabular}{lccc}
\hline$\leq 2$ & 7 & 5 & 12 \\
\hline$>2-5$ & 23 & 21 & 44 \\
\hline$>5$ & 24 & 28 & 52 \\
\hline Median (IQR) (years) & $4.1(2.6-8.3)$ & $5.1(3-9)$ & $4.6(2.8-9)$ \\
\hline
\end{tabular}

$\mathrm{IQR}=$ interquartile range.

*Parents and children.

†Nuclear family plus wider family living together. 
$200 \mathrm{mg}$ tablets, respectively. Treatment started at a low weight related dose and was increased after two weeks following the WHO recommendation. ${ }^{23}$ Starting and initial maintenance doses were $1.5 \mathrm{mg} / \mathrm{kg} /$ day and $3 \mathrm{mg} / \mathrm{kg} /$ day for phenobarbital and $5 \mathrm{mg} / \mathrm{kg} /$ day and $16 \mathrm{mg} / \mathrm{kg} /$ day for carbamazepine taken in two divided doses daily. Drugs were administered either to a maximum of $4 \mathrm{mg} / \mathrm{kg}$ and $20 \mathrm{mg} / \mathrm{kg}$ daily, respectively, or until seizure were controlled. If seizures were not controlled despite a full dose and a blood concentration within the therapeutic range, or if there were intolerable side effects, treatment was changed to the other study drug, with weaning from the first drug, and the child withdrawn from the behavioural outcome analysis. If there was still no improvement in seizure control a third antiepilepsy drug was used. All children were followed up for a minimum of 12 months.

Table 2 | Characteristics of children with epilepsy and their families according to allocation to antiepilepsy drug ( 54 children in each group): details of seizures and other problems. Figures are numbers of children unless stated otherwise

\begin{tabular}{|c|c|c|c|}
\hline & Phenobarbital & Carbamazepine & Total \\
\hline \multicolumn{4}{|l|}{ Classification of seizures: } \\
\hline Generalised & 29 & 22 & 51 \\
\hline Partial & 25 & 32 & 57 \\
\hline \multicolumn{4}{|l|}{ Aetiological classification: } \\
\hline Without other impairment & 40 & 31 & 71 \\
\hline Symptomatic* & 14 & 23 & 37 \\
\hline \multicolumn{4}{|c|}{ Duration of seizures before start of regular drug treatment (years): } \\
\hline 1 & 27 & 23 & 50 \\
\hline$>1-2$ & 16 & 13 & 29 \\
\hline $22-3$ & 5 & 8 & 13 \\
\hline $13-5$ & 2 & 4 & 6 \\
\hline$>5$ & 4 & 6 & 10 \\
\hline Median (IQR) (months) & $13(3-25)$ & $16(4.5-30)$ & $15(3-30)$ \\
\hline \multicolumn{4}{|c|}{ Baseline mean behavioural scores $(95 \% \mathrm{Cl})$ : } \\
\hline BSID & 100.00 (72.99 to 127.11$)$ & 109.33 (84.20 to 134.46$)$ & - \\
\hline Richman & 31.17 (20.00 to 31.44$)$ & 31.58 (21.64 to 40.52$)$ & - \\
\hline CPRS-R:S & 61.33 (55.05 to 73.10 ) & 57.39 (51.57 to 63.21$)$ & - \\
\hline
\end{tabular}

No of seizures in previous year:

\begin{tabular}{llll}
\hline$\ll 10$ & 18 & 21 & 39 \\
\hline $10-20$ & 15 & 15 & 30 \\
\hline 120 & 21 & 18 & 39
\end{tabular}

Previous treatment with antiepilepsy drug:

\begin{tabular}{llll} 
No & 42 & 40 & 82 \\
\hline Yes & 12 & 14 & 26 \\
\hline
\end{tabular}

Motor impairment:

\begin{tabular}{lccc}
\hline Absent & 45 & 45 & 90 \\
\hline Present & 9 & 9 & 18 \\
\hline Cognitive impairment: & 37 & 37 & 74 \\
\hline Absent & 17 & 17 & 34 \\
\hline Present & & & 86 \\
\hline Pre-existing behavioural problems: & 43 & 43 & 22 \\
\hline Absent & 11 & 11 & \\
\hline Present & 0 inf
\end{tabular}

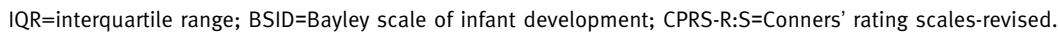
*Includes cryptogenic.

\section{Outcome measures}

Our main outcome measure was behavioural side effects after one year's treatment, assessed by comparing the results of the two behavioural assessments. Seizure outcome was measured as "seizure remission," defined as no seizures during the last quarter of 12 month follow-up. Drug efficacy was assessed by date of treatment allocation, time to first seizure after randomisation, time to withdrawal from treatment because of adverse effects, and date of last follow-up.

\section{Analysis}

We carried out intention to treat analysis for seizure outcome. Our primary aim was to compare the side effects of the drug, which required children to take that drug up to the time of behavioural reassessment but we noted any reasons for discontinuing treatment. We measured differences in behavioural side effects using independent sample $t$ tests and Mann-Whitney tests. Paired sample $t$ tests were used to compare the difference between behavioural assessment scores before and after treatment within the trial groups. We compared drug efficacy using time to first seizure after randomisation as the primary data. Actuarial (KaplanMeier) techniques were applied to the intervals from randomisation to first seizure, date of last follow-up when no seizures were recorded, or time to drug withdrawal. We used multiple logistic regression analysis to assess significant relations between behavioural side effects and individual variables such as age, sex, minor motor impairment, cognitive impairment, and pre-existing behavioural problems.

\section{RESULTS}

The figure shows the flow of children through the trial. Tables 1 and 2 show the characteristics of the families and children and the classification of seizures and epilepsy at randomisation. Most children came from poor and middle income families in rural areas without automobile access or made up roads and thus travel was by walking or boat, and this was fairly representative of the general population. Clinic visits often involved great effort and sometimes hardship. The male to female ratio was 1.3:1 in the whole population, but more girls were allocated to carbamazepine. Mean and median age at randomisation and at onset of seizures was higher in the carbamazepine group (table 1).

Over four fifths of children had their first non-febrile seizure after the age of 1 year. Two in the carbamazepine group and one in the phenobarbital group had a history of a prolonged seizure with fever, but the other children had no history of convulsive status. There were more generalised seizures in the phenobarbital group, and more partial seizures in the carbamazepine group. The seizure rate and total number of seizures during the previous year were higher in the phenobarbital group (table 2). Median duration of epilepsy was longer by three months in the carbamazepine group. Three quarters of the children had never had daily long term treatment with antiepilepsy drugs, while the 


\begin{tabular}{|c|c|c|c|}
\hline & Phenobarbital & Carbamazepine & Total \\
\hline \multicolumn{4}{|l|}{ Compliance with visits: } \\
\hline Regular & 29 & 35 & 64 \\
\hline Positive recalled* & 13 & 14 & 27 \\
\hline Negative recalled $\dagger$ & 12 & 5 & 17 \\
\hline \multicolumn{4}{|l|}{ Drug compliance: } \\
\hline Continued assigned drug & 40 & 45 & 85 \\
\hline Changed drug & 2 & 4 & 6 \\
\hline \multicolumn{4}{|l|}{ Behavioural outcome: } \\
\hline No change & 28 & 31 & 59 \\
\hline Improved & 8 & 8 & 16 \\
\hline Deteriorated & 4 & 6 & 10 \\
\hline \multicolumn{4}{|l|}{ Behavioural problems: } \\
\hline Mild & 3 & 3 & 6 \\
\hline Unacceptable & 1 & 3 & 4 \\
\hline \multicolumn{4}{|c|}{ No with behavioural problems/total in group: } \\
\hline Female & $3 / 9$ & $4 / 28$ & $7 / 37$ \\
\hline Male & $1 / 31$ & $2 / 17$ & $3 / 48$ \\
\hline \multicolumn{4}{|l|}{ Age at first presentation (years)*: } \\
\hline 2 & $1 / 6$ & $0 / 4$ & $1 / 10$ \\
\hline $22-5$ & $0 / 18$ & $5 / 19$ & $5 / 37$ \\
\hline$>5$ & $3 / 16$ & $1 / 22$ & $4 / 38$ \\
\hline \multicolumn{4}{|l|}{ Seizures at 1 year (in all children): } \\
\hline $\begin{array}{l}\text { None in the } 3 \text { months before end } \\
\text { of follow-up }\end{array}$ & 32 & 39 & 71 \\
\hline $\begin{array}{l}\text { None in the } 6 \text { months before end } \\
\text { of follow-up }\end{array}$ & 19 & 27 & 46 \\
\hline None since started treatment & 3 & 4 & 7 \\
\hline
\end{tabular}

*Missed several follow-ups but could be traced.

†Missed several follow-ups and could not be traced.

remainder had had a minimum of three months' treatment. Associated minor motor and cognitive comorbidities were similar in the groups (table 2). Seventy four children had a normal IQ (74), and 43 in each group had normal behaviour before treatment.

\section{Behavioural side effects and seizure outcome}

Table 3 gives details of the outcome at one year. In 59 children there was no change in behaviour, and in 16 behaviour improved. Ten children experienced excessive restlessness and hyperactivity $(4 / 54)$ in the phenobarbital group and 6/54 in the carbamazepine group (difference 3.7\%). Table 4 shows the mean difference between behavioural assessment scores before and after treatment. There was a significant

Table 4 | Mean differences (95\% confidence interval)* in the behavioural test scores before and after treatment within the trial group

\section{Phenobarbital}

Carbamazepine

BSID (2 years $\dagger$ ) $-2.83(-7.16$ to 1.49$), P=0.153(n=6)$ $2.67(-6.26$ to 8.76$), P=0.633(n=4)$

Richman (>2-5 years $\dagger$ ) 5.44 (1.09 to 9.80), $P=0.017(n=18)$ 5.00 (0.65 to 7.15), $P=0.021(n=19)$

CPRS-R:S (>5-15 yearst) 4.40 (-4.36 to 13.16), $P=0.348(n=16) \quad 4.30(-64$ to 5.92), $P=0.109(n=22)$

BSID=Bayley scale of infant development; CPRS-R:S=Conners' rating scales-revised.

*Paired $t$ test for behavioural score before and after treatment within trial group.

†Age group on presentation. improvement in behaviour after regular treatment with antiepilepsy drugs in both groups of 2-5 year olds. There were no significant differences between the mean, median, and range of behavioural outcome scores or between the two groups by independent $t$ test (table 5). Logistic regression analysis showed no association between the outcome behaviour and age, sex, motor disability, cognitive developmental delay, antiepilepsy drugs, or pre-existing behavioural problems (table 6).

One child in the carbamazepine group withdrew after four months because of severe headaches and aggressive outbursts. Another child in the carbamazepine group experienced occasional severe headaches. At the initiation of treatment three in the phenobarbital group and one in the carbamazepine group experienced disturbed sleep. Also in the phenobarbital group one child reported irritability and four had gastrointestinal disturbances.

Seizures became worse (increased and evolving to myoclonic seizures) in three in the carbamazepine group (two were shifted to phenobarbital and one to a third antiepilepsy drug as there was no improvement of seizure control after the shift to the other trial drug). Two in the phenobarbital group had poor seizure control with full dose and then shifted to the carbamazepine with good results (see figure). Three children taking phenobarbital and four taking carbamazepine discontinued the drug for more than seven days for various reasons - for example, returning home, running out of drugs, and substituting homoeopathic treatment. Of these, four children had convulsive status epilepticus while not taking the drug (two in each group), three within 7-10 days and one after 30 days after they stopped taking the drug. All were admitted to hospital and restarted treatment. Fifty three children remained without seizures for six months to one year, and another 18 were seizure free during the three months before the one year follow-up (table 3). Seven (6.5\%) children were seizure free from the time of initial treatment. An additional 39 (36\%) were seizure free for the six months before the final assessment and 25 more were seizure free for the last three months, so the total who were seizure free for the last three months was $71(66 \%)$ (table 3).

Actuarial analysis estimated the mean time without seizures was 102 days for phenobarbital and 74 days for carbamazepine. The cumulative seizure curves for children in both groups showed no difference in efficacy.

\section{DISCUSSION}

In this trial we found no significant difference in behavioural side effects with phenobarbital and carbamazepine using objective masked assessments and parental reporting in children with epilepsy without severe additional impairment. Our study was designed to find at least a 25\% difference at 5\% level. Ten children showed deterioration of behavioural state, of whom four received phenobarbital and six carbamazepine. Intolerable behavioural problems were more common 
Table 5 Independent $t$ test showing difference between mean final behavioural score for children with epilepsy treated with phenobarbital or carbamazepine

\begin{tabular}{lcc} 
& Difference in mean $(95 \% \mathrm{Cl})$ & P value \\
BSID & $-12.08(-13.58$ to 19.41$)$ & 0.50 \\
\hline Richman & $0.95(0.78$ to 13.53$)$ & 0.16 \\
\hline CPRS-R:S & $-0.24(-10.16$ to 9.67$)$ & 0.96
\end{tabular}

BSID=Bayley scale of infant development; CPRS-R:S=Conners' rating scales-revised.

with carbamazepine, and sleep disturbance and gastrointestinal problems were more common with phenobarbital. Headache and worsening of seizures were common with carbamazepine, but the differences between the groups with respect to side effects were not significant. Behaviour improved in 16 children (eight in each group), probably reflecting a reduced burden of seizures, improved sleep and feeding, and reduced irritability.

\section{Comparison with other studies}

Our population characteristics are similar to those in studies in Kenya and India with high rates of seizures. Our results support the findings from those two resource poor countries and from one study in a developed country where no severe behavioural side effects with phenobarbital were found. ${ }^{10-12}$

A trial in the United States in children with partial seizures found no difference in behavioural or cognitive effects between the two drugs. ${ }^{12}$ In the North American cross-balanced randomised controlled trial of phenobarbital versus valproate in 28 children of normal intelligence with relatively mild seizure disorders, the authors found only marginal difference in hyperactivity between the two drugs, which was subtle and not clinically identified. ${ }^{6}$

In a trial in the United Kingdom, de Silva et al studied four antiepilepsy drugs (phenobarbital,

Table 6 | Main effect model showing correlation between behavioural problem at one year and individual variables by using logistic regression with mutually adjusted odds ratios

\begin{tabular}{|c|c|c|c|}
\hline Variables & $\begin{array}{c}\text { No with behavioural problems/ } \\
\text { Total }\end{array}$ & Odds ratio $(95 \% \mathrm{Cl})$ & $P$ value \\
\hline \multicolumn{4}{|l|}{ Age (years): } \\
\hline $2-5$ & $5 / 47$ & 1 & \\
\hline$>5$ & $5 / 38$ & 0.99 (0.98 to 1.01$)$ & 0.79 \\
\hline \multicolumn{4}{|l|}{ Sex: } \\
\hline Male & $3 / 48$ & 3.38 (0.83 to 3.88$)$ & 0.08 \\
\hline Female & $7 / 37$ & 1 & \\
\hline \multicolumn{4}{|c|}{ Cognitive impairment: } \\
\hline Absent & $7 / 57$ & 1 & \\
\hline Present & $3 / 28$ & $0.98(0.95$ to 1.00$)$ & 0.19 \\
\hline \multicolumn{4}{|c|}{ Minor motor impairment: } \\
\hline Absent & $9 / 71$ & 1 & \\
\hline Present & $1 / 14$ & $2.49(0.55$ to 11.13$)$ & 0.23 \\
\hline \multicolumn{4}{|c|}{ Pre-existing behavioural problems: } \\
\hline None & $9 / 68$ & 1 & \\
\hline Yes & $1 / 17$ & $1.00(0.19$ to 5.20$)$ & 1.00 \\
\hline Total & $10 / 85$ & - & \\
\hline
\end{tabular}

carbamazepine, phenytoin, and valproate) in children with relatively mild seizure disorders, with most having had fewer than 10 seizures before randomisation. ${ }^{5}$ The phenobarbital arm of the study was stopped when six of the first 10 children were reported to have unacceptable behavioural side effects. There were widespread views about such effects in children, which resulted in the phenobarbital arm of the trial being stopped. The study, however, did not use a standardised behavioural assessment tool.

The Los Angeles study found marked behavioural problems in more than $30 \%$ of the children with febrile seizures treated with phenobarbital compared with those untreated. ${ }^{7}$ These would be younger, usually normal children and no behavioural scale was used.

Although total numbers are not large, all these together suggest that behavioural side effects are reported less often in countries with limited resources than in more affluent countries. The children in our study were mainly from rural areas, and cost of travel was an important factor in long term compliance, suggesting the need for a community based service for the children with epilepsy. The characteristics related to seizures and epilepsy in our study were comparable with those in other studies in countries with limited resources. ${ }^{1011}$

Age at randomisation, characteristics of seizures, and associated prognostic features - that is, age at first seizure, total number of seizures before start of treatment, and associated non-convulsive disorders- differed in our study population compared with study populations in developed countries. Proportions of seizure types, however, were comparable with those in the UK and Indian studies. Four out of seven children who stopped medication had convulsive status epilepticus. This was probably because of withdrawal of the drug as only three had a history of febrile status epilepticus. The treatment was effective, despite the high rate of seizures and length of history, in that $78 \%$ had total remission and another 11\% more than $80 \%$ remission after one year. Rate of seizure remission in other studies varied from $67 \%$ to $73 \%$. $^{1029}$

In Kenya, Feksi et al included children and adults with a similar background of high frequency of seizures and time between the onset of seizures and starting appropriate treatment. ${ }^{10}$ Over half $(53 \%)$ were seizure free in the 6-12 month follow-up period; this was 51\% in our study. In a US study of children treated with phenobarbital, $67 \%$ with partial seizures were seizure free after one year of treatment ${ }^{12}$ compared with $78 \%$ in our study. In the Northern Ecuador study $65 \%$ were seizure free at 6 months and $72.7 \%$ at one year. ${ }^{29}$

\section{Conclusions}

From this study in Bangladesh, we conclude that phenobarbital is not associated with excess behavioural side effects when compared with carbamazepine and is therefore an effective and suitable drug to use for children with epilepsy in this setting. 


\section{WHAT IS ALREADY KNOWN ON THIS TOPIC}

Phenobarbital is a highly effective antiepilepsy drug recommended by WHO for use in countries with limited resources

Several studies in developed countries have shown a high rate of behavioural side effects with phenobarbital

\section{WHAT THIS STUDY ADDS}

Phenobarbital was not associated with a high rate of behavioural side effects in children in Bangladesh
8 Wolf SM, Forsyth A, Stundent AA. Long-term effect of phenobarbital on cognitive function in children with febrile convulsions. Pediatrics 1981;68:820-3.

9 Farewell JR, Lee YJ, Hirtz DG, Sulzbacher SI, Ellenberg JH, Nelson KB. Phenobarbital for febrile seizures-effect on intelligence and on seizure occurrence. N Engl/ Med 1990;322:364-9.

10 Feksi AT, Kaamugisha J, Sander JWAS, Gatiti S. Comprehensive primary health care antiepileptic drug treatment programme in rural and semi-Urban Kenya. Lancet 1991;337:406-9.

11 Pal DK, Das T, Chaudhuri G, Johnson AL, Neville BGR. Randomized controlled trial to assess acceptability of phenobarbital for childhood epilepsy in rural India. Lancet 1998;351:19-23.

12 Wendy G. Carbamazepine versus phenobarbital for partial onset seizures in children. Epilepsia 1987;28:56-60.

13 Kwan P, Brodie MJ. Phenobarbital for the treatment of epilepsy in the 21st century; critical review. Epilepsia 2004;45:1141-9.

We thank Stewart Boyd for his help and support, A L Johnson for his advice in statistical analysis, and Dhaka Shishu (Children's) Hospital authority for providing logistic support

Contributors: SHB was principal investigator, designed and organised the study, analysed the data under the supervision of BN and NZK, and wrote the paper as part of her PhD. MJ developed strategies to improve compliance and to distribute appropriate service for families and contributed to data collection and data entry. SF tested reliability and validity of the behavioural assessment scale. SF and UKK performed psychological and behavioural tests and compiled data for analysis. NZK shared the project plan implementation and directly supervised and provided support to run the project in Dhaka Shishu Hospital. BN shared in the study design, supervised the project and data analysis, helped in writing the paper, and is guarantor.

Funding: Department for International Development (DFID) administered through the British Council, Dhaka, and UK

Competing interests: None declared.

Ethical approval: Research ethics committee of Great Ormond Street Hospital NHS trust and the Institute of Child Health London and the ethical review committee of Bangladesh Institute of Child Health.

1 Shorvon SD, Farmer PJ. Epilepsy in developing countries: a review of epidemiological, sociocultural and treatment aspects. Epilepsia 1988;29(suppl 1):S36-54.

2 WHO. Initiative of support to people with epilepsy. Geneva: WHO, 1990 (WHO/MHH, MND/90.3).

3 Gastaut H, Osontokun BO. Proposals on antiepileptic pharmacotherapy for use in developing countries. Epilepsia 1976;17:355-60.

4 Banu SH, Khan NZ, Hossain M, Jahan A, Parveen M, Rahman N, et al. Profile of childhood epilepsy in Bangladesh. Dev Med Child Neurol 2003;45:477-82.

5 de Silva M, MacArdle B, McGowan M, Hughes E, Stewart J, Neville BG, et al. Randomised comparative monotherapy trial of phenobarbitone, phenytoin, carbamazepine or sodium valproate for newly diagnosed childhood epilepsy. Lancet 1996;347:709-13.

6 Vining PG, Mellits ED, Dorsen MM, Cataldo MF, Quaskey SA, Spielberg SP, et al. Psychologic and behavioural effects of antiepileptic drugs in children: a double blind comparison between phenobarbital and valproic acid. Pediatrics 1987;80:165-74

7 Wolf SM, Forsyth A. Behavioural disturbance, phenobarbital, and febrile seizures. Pediatrics 1978;61:728-31.
14 Kale R, Perucca E. Revisiting phenobarbital for epilepsy. BMJ 2004;329:1199-200.

15 Machin D, Campbell MJ, Fayer PM, Pinol A. Sample size tables for clinical studies. 2nd ed. Oxford: Blackwell Science, 1997:13.

16 Commission on Classification and Terminology of International League Against Epilepsy. Proposal for revised classification of epilepsies and epileptic syndromes. Epilepsia 1989;30:389-99.

17 Commission on Epidemiology and Prognosis, International League Against Epilepsy. Guidelines for epidemiologic studies on epilepsy. Epilepsia 1993;34:592-6.

18 Egan DF. Developmental examination of infants and preschood children. Oxford: Blackwell Science, 1990.

19 Bayley N. Manual for Bayley scales of infant development. 2nd ed. New York: Psychological Corporation, 1993.

20 Munir SZ, Zaman S, McConachie H. Development of an independen assessment scale for Bangladesh. J Appl Res Intellec Disabl 1999;12:241-52.

21 Huq S. Standardization of the Wechsler intelligence scale for children (translation and adaptation in Bangla) in Dhaka City. In: Sultana SZ, ed. Scientific studies on developmental disabilities in Bangladesh. Dhaka: Bangladesh Protibondhi Foundation, 1994:183-96.

22 WISC-R. Manual of Wechsler intelligence scale for children-revised. New York: Psychological Corporation, 1971.

23 Durkin M, Khan N, Davidson LL, Zaman SS, Stain ZA. Effect of natural disaster in children: effect of post traumatic stress. Am J Public Health 1993;83:1549-53.

24 Richman N, Graham P, Stevenson J. Pre-school to school: $a$ behavioural study. New York: Academic Press, 1982.

25 Conners CK. Manual for Conners' rating scale-revised; teaching manual. New York: Multi-Health Systems, 1997.

26 Banu SH. Clinical profile predictors of outcome and randomised controlled trial of efficacy and side effects of drug treatment [PhD thesis] London: University College London, 2003.

27 Rutter M. A children's behaviour questionnaire for completion by teachers: preliminary findings. / Child Psychol Psychiatr 1967;8:1-11.

28 Rutter M, Graham P, Yule WA. A neuropsychiatric study in childhood. Philadelphia: JB Lippincott, 1970.

29 Placencia M, Sander JW, Shorvon SD, Roman M, Alarcon F, Bimos C, et al. Antiepileptic drug treatment in a community health care setting in northern Ecuador: a prospective 12 months assessment. Epilepsy Res $1993 \cdot 14: 237-44$

Accepted: 16 October 9999 